\title{
Discrete Event Simulation and Virtual Reality Use in Industry: New Opportunities and Future Trends
}

\author{
Christopher J. Turner, Member, IEEE, Windo Hutabarat, John Oyekan, Member, IEEE, \\ and Ashutosh Tiwari, Member, IEEE
}

\begin{abstract}
This paper reviews the area of combined discrete event simulation (DES) and virtual reality (VR) use within industry. While establishing a state of the art for progress in this area, this paper makes the case for VR DES as the vehicle of choice for complex data analysis through interactive simulation models, highlighting both its advantages and current limitations. This paper reviews active research topics such as VR and DES real-time integration, communication protocols, system design considerations, model validation, and applications of VR and DES. While summarizing future research directions for this technology combination, the case is made for smart factory adoption of VR DES as a new platform for scenario testing and decision making. It is put that in order for VR DES to fully meet the visualization requirements of both Industry 4.0 and Industrial Internet visions of digital manufacturing, further research is required in the areas of lower latency image processing, DES delivery as a service, gesture recognition for VR DES interaction, and linkage of DES to real-time data streams and Big Data sets.
\end{abstract}

Index Terms-Augmented reality (AR), computer simulation, human-computer interaction, virtual reality (VR).

\section{INTRODUCTION}

$\mathbf{S}$ INCE their inception, the fields of discrete event simulation (DES) and virtual reality (VR) have pursued different evolutionary paths. With advances in computational power in recent years, the possibility of the combined use of these two tools has grown. While this growth has been noted in the variety of papers now available, there still exists a need to bring together a common framework for the joint use or translation of 2-D models into 3-D representations of dynamic systems and the appropriateness of such a shift in DES model representation.

In a previous work, Akpan and Brooks [1] examined the promise, at that point in time, VR presented to developers of DES models. Akpan and Brooks [1] put forward the notion of VR-based DES or VRSIM. The views of then current DES only modelers and their reaction to the use of VR in their work are illustrated, noting that their initial enthusiasm in the potential of VR was tempered by the longer learning curve of 3-D modeling and the limitations of VR experienced at the time [1].

Manuscript received November 13, 2015; revised February 9, 2016 and May 20, 2016; accepted June 28, 2016. This work was supported in part by Innovate UK through Project 101888, in part by the Engineering and Physical Sciences Council under Grant EP/M506813/1, in part by Alstom Ltd., and in part by Lanner Group Ltd. This paper was recommended by Associate Editor Y. Liu.

The authors are with the Manufacturing Informatics Centre, Manufacturing and Materials Department, Cranfield University, Bedford, MK43 0AL, U.K. (e-mail: c.j.turner@cranfield.ac.uk; w.hutabarat@cranfield.ac.uk; j.o. oyekan@cranfield.ac.uk; a.tiwari@cranfield.ac.uk).

Color versions of one or more of the figures in this paper are available online at http://ieeexplore.ieee.org.

Digital Object Identifier 10.1109/THMS.2016.2596099
The early interest in the VR DES combination has in part been reignited by developments in the manufacturing sector and the move to digital manufacturing encompassed by the "Smart Factory" model envisioned as part of the Industry 4.0 Agenda and the notion of "Brilliant Factories" proposed by GE and other large manufacturers part of the Industrial Internet consortium. The Smart Factory concept has been used to describe a manufacturing plant that features network-connected smart machines, data repositories, and integrated sensing technologies to provide human-responsive context-aware production lines [85]. Similarly, Radziwon et al. [86] describe this concept as providing flexibility in the manufacturing process based on real-time consumer demand. The Industrial Internet also describes the use of intelligent networked machines and the use of advanced analytics in the provision of adaptable internet-connected production systems [85]. Both of the aforementioned concepts rely on the ability for manufacturing systems to be visualized in real time. The need for decision making and support services to be integrated into such envisioned systems provides a role for the VR DES combination.

The practice of DES has been in existence for more than 50 years. In this time, a range of software systems have been created as environments for this type of simulation [2]. Commercial packages such as Lanner Witness, Arena, and Simul8 are popular for the development of DES models along with open-source environments such as DESMO-J. In terms of VR, while the origin of hardware and interaction devices can be traced back to as early as the 1960s [3], the software in use with DES systems today is the product of much more recent developments in computer graphics rendering. One example of VR software is provided by Virtalis, called Visionary Render; this software has been used in conjunction with Lanner Witness to provide immersive 3-D representations of DES models. VR seeks to imbue users with a sense of presence in a synthetic environment generated by a computer system. VR systems typically implement the architecture depicted in Fig. 1. In such systems, users' actions in the real world are captured through the VR input interface system (through input devices such as 3-D mouse and other handheld pointing devices) and transferred into the VR computing system. The VR system then calculates and implements the adjustments to be made to the virtual environment. These adjustments are fed back to the user through the VR output interfaces, which can be visual, audio, and haptic in nature.

Past VR systems were typified by static installations such as the immersive cave automatic virtual environment (CAVE) system (see Fig. 2). However, over the past few years, there 


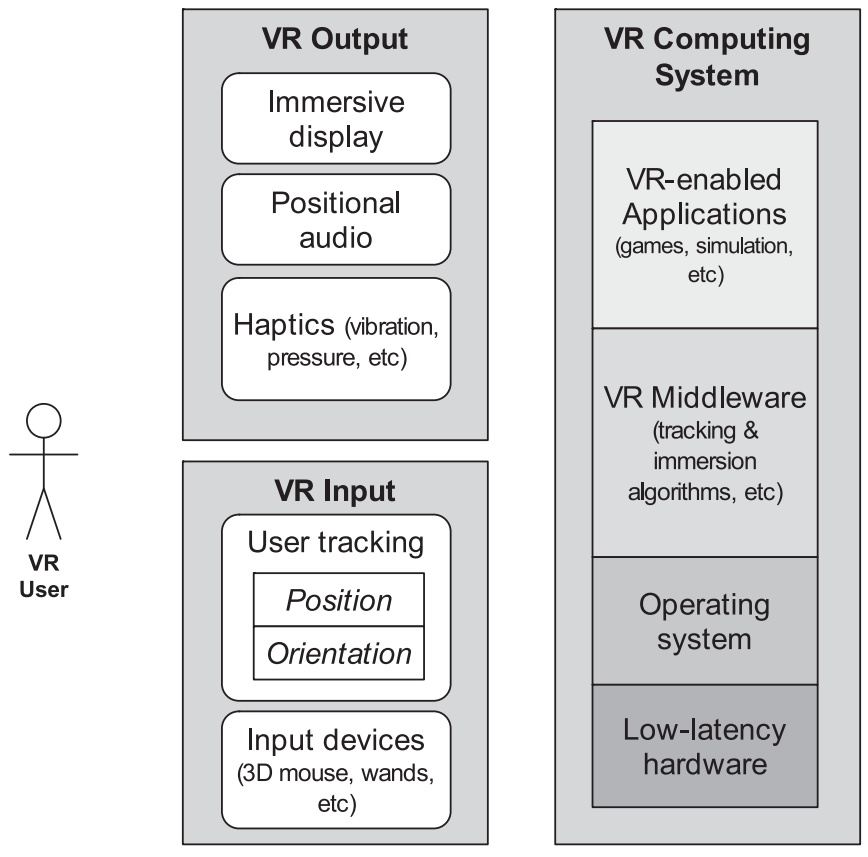

Fig. 1. Architecture of a typical VR system.

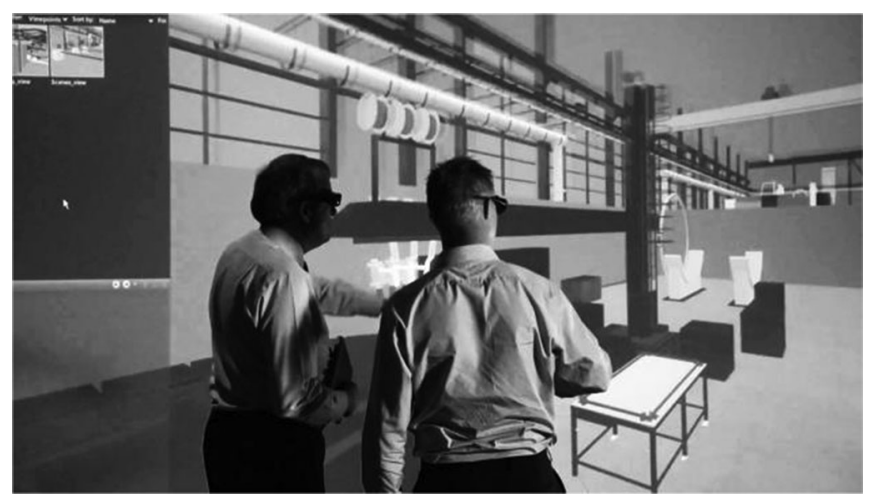

Fig. 2. Typical CAVE system. Image courtesy of Lanner Group.

has been a great deal of development on consumer-level VR technologies, pioneered by the Oculus system (see Fig. 3) (that provides users with an immersive visual experience through the use of a headset). Due to these developments, an increase in the use of VR in a range of applications can now be expected. This paper aims to review the area of VR and DES to examine the changes in the technologies and their acceptance over the last ten years in so doing identifying advantages and limitations for potential users of this technology combination. Furthermore, concepts such as virtual and smart factories are examined along with issues of VR DES integration, DES model validation, and verification with VR and application development. An analysis of future trends, highlighting potential opportunities for the use of this technology combination in industry, is presented.

\section{INITIAL WORKS}

From its theoretic inception in the late 1960s [4], VR use has grown to encompass a wide variety of applications. The

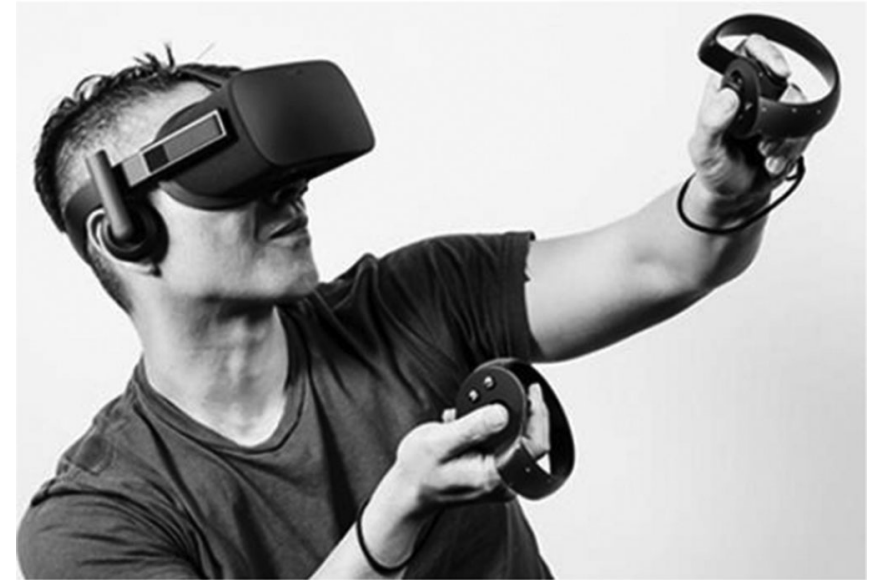

Fig. 3. Oculus Rift system, showing the immersive HMD with headphones, and the Oculus Touch input interface.

notion of VR and DES has been present since the late 1990s; an example work can be found in [5], in which Page and Smith examine the use of DES in the production of military training simulations. Mention is given in this paper to virtual and live simulations. An example of a virtual simulation is given as a flight simulator used to train pilots. Although 3-D environments are not explicitly discussed in this paper, many of the model interaction types are in that human motor control skills and their inputs into a virtual simulation are seen as key. In addition, the research of Kelsick and Vance [6] points toward the adoption of 3 -D visualization and virtual interactions with simulation models as the new paradigm for factory management and decision making, the acceptance of which is echoed later on by Waurzyniak [7]. The use of VR in combination with other established software tools is exemplified in the work of Steffan et al. [8] who look at its use in combination with CAD/CAM tools. This work describes the savings in time such a system can offer against the fabrication of physical prototypes. Interestingly, this work points to the need for the ability to simulate physical feedback from virtual objects, a need which is being addressed by the development of VR interaction devices. The early promise of the work completed in the 1990s has led to more recent advances, partly due to greater computing power put to use in the processing of larger amounts of data in shortened periods of time. This trend is evident in the work of Leu et al. [9] who expand on the use of human-computer interface technologies for CAD and VR combined use (the use of interaction devices with VR and DES is expanded on in Section VII).

Kim et al. [10] note, in part, the opportunities offered to DES through web-based simulations. Various technologies, many based on extensible markup language (XML), are discussed along with the provision of a web-based modeling framework composed of best of breed techniques and technologies. Fishwick [11] continues this discourse introducing the need for information fusion in the integration of existing DES models from different areas though the use of a unifying 3-D environment, citing the relevance to defense and military use cases. Waller and Ladbrook [12] make the case for VR and DES simulation 


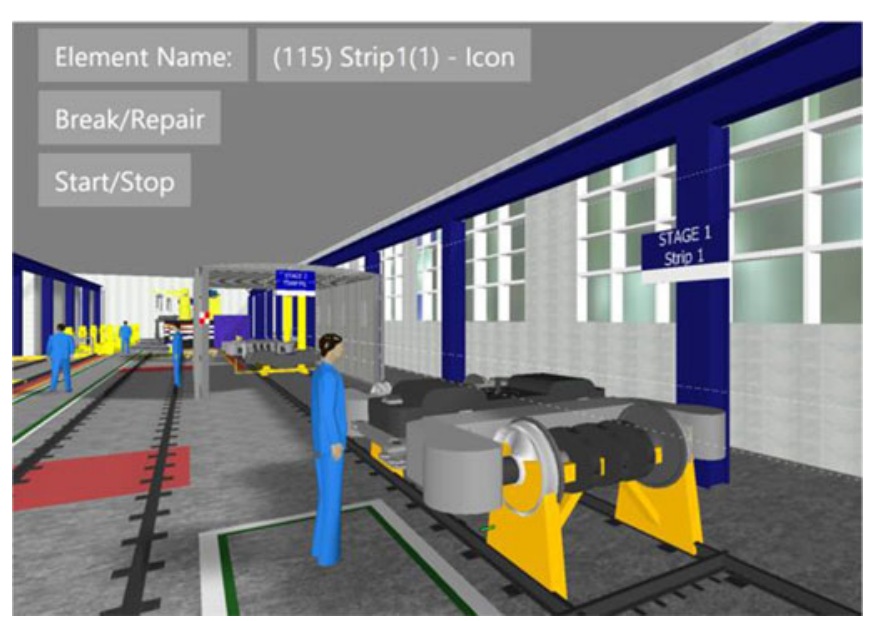

Fig. 4. Example of a Virtual factory in Witness VR environment.

presenting the initial version of the WitnessVR simulation package (see Fig. 4) and its use in simulating factory production lines.

While pointing out the limitation of VR in addressing mathematical simulation challenges, it is noted that the ease of understanding and enhanced ability to explore simulation models provides benefits at the corporate management decision-making level [12]. Another early proponent for DES VR is Kelsick et al. [6], [13] who outline the use of a CAVE for the 3-D visualization of DES models [13]. In this research, haptic movements are related to changes and object movements in the DES model. This work explored the effect of models presented in a virtual format on users not familiar with DES. Freund and Schluse [14] raise the point that for some, the combination of VR, DES, and control technology poses major compatibility problems for developers. As such, they propose the use of state-oriented modeling to develop integrated 3-D DES systems. Based on the Petri net formalization, state-oriented modeling facilitates the effective description of both static and dynamic elements of a system. This paper also outlines projective VR methods that aim to determine the control inputs of users from their inputs in order to translate those actions into movements in controlled plant and machinery [14]. Zhong and Shirinzadeh [15] put forward a framework for using 3-D animation to represent an existing DES model. Zhong and Shirinzadeh [15] make the case for 3-D visualization of DES highlighting its advantages in describing complex engineering issues and the ability to view a solution from multiple angles. This paper proposes a methodology for translating between 2-D DES and 3-D animation.

Dangelmaier et al. [16] raise the issue of real-time decision making and its reflection in the visualization of a simulation. In this work, a two-tier framework is outlined for real-time immersive presentation of a simulation model for material flow. This paper also explores the point in time which a user can best interact with a virtual simulation, examining the notion of presimulation, where some calculations are made offline to model elements of certain scenarios in advance. Cunha et al. [17] promote the use of VR and DES for the real-time joint exploration of models by users who are geographically separate from each other. Such remote working, linking disparate factories and research centers of an organization, can lead to cost savings in travel and can help to offset the initial cost of investing in (at that time) expensive VR hardware. One of the initial papers to explore the use of DES with augmented and mixed reality environments is that of Lektauers [18]. A discrete event system specification is put forward in this paper that utilizes mixed reality to execute DES models in a 3-D environment. Called visual-DEVS, the specification provides a mode to integrate video of a live environment and superimpose 3-D computer animation.

Robinson [19] made the case, back in 2004, that the rapid advances in computer technology made a review of existing simulation methodologies an urgent task. A particular concern in this paper is the rise in the use of web technologies reflected against the lack of uptake of this method of delivery in the simulation community. In the following sections of this paper, the latest research in DES and VR use is examined in line with the challenges that still remain.

Nielebock et al. [20] make a compelling case for combined DES and VR use through their assertion that through the use of both tools, additional aspects about the model may be learnt that are not obvious from the use of DES alone. In this way, VR and DES can provide a much more detailed description of a situation from a wider variety of viewpoints in their combined use. In alternative work, Fumarola et al. [21] discuss the development of a library of DES model components that may be described in 2-D and 3-D form. In separating the 3-D visualization from the DES model, loosely coupled animation sequences for model elements may be swapped in with little or no development expense. Fumarola et al. [21] point to their 3-D simulation environment as an example; this prototype makes use of XML descriptions of CAD models in order to aid the correct identification, description, and visualization of DES model elements as 3-D animations. In addition, the work of Rekapalli and Martinez [22]-[26] and Fumarola et al. [21] involves DES and the integration of 3-D animations for construction industry applications, putting forward ways of linking the two tools.

The summary provided by the studies of Akpan and Brooks [1], [27] gives a good indication of the value of VR DES combined systems. Akpan and Brooks [1] confirm that DES and VR used together allow for the identification of more modeling errors and omissions than with DES alone. In the practitioners' survey [1], it was found that the ease of understanding afforded by VR DES models and the notional decision-making quality achieved from them was higher than with a 2-D model [27]. This study showed that the time taken to develop 3-D models was longer than with 2-D [27]. The message from surveys in this area is that VR DES combinations allow both a modeler and the user to better understand a subject area than would otherwise be possible with 2-D alone [28].

In the completion of an analysis of papers, with the search term "DES" and "VR," it was found that there are 129 papers published between 1994 and 2015 that detail the use of both DES and VR together, with $23 \%$ of those articles relating to construction while only $15 \%$ described scenarios involving manufacturing. 
Construction bears much similarity with manufacturing. Both involve the use of processes and machines to develop end products. A survey of the use of visualization technology and DES was conducted. The output of the survey demonstrated that there is still scope for the use of DES and VR for the optimization of factory layouts in manufacturing.

As mentioned earlier, VR and DES use from its inception in the early 1990s has evolved gradually over time. A recent increase in interest has prompted the research in this paper, with the aim of ascertaining the trends that are being established now and for the future regarding this technology combination. From this research, it was possible to develop categories for the latest research being undertaken along with the context and roots provided by earlier works; these are the drivers for increased VR DES take up and shape the literature survey undertaken as part of this research.

A paradigm that has been building for some time now is that of the virtual factory. This first category concerning the holistic modeling of factories is one of the major drivers behind increased interest in VR DES. The possibility of real-time use of VR DES is the second category and enabled advances in computing power and the ever-shortening amounts of time taken between sensor data provision, processing, analysis, and visual rendering. The third category introduces advances in VR though $\mathrm{AR}$ and mixed reality also made possible by the aforementioned improvements in latency. Progress in VR DES communication has also been made, and this is the subject of Section IV. VR DES Interaction devices have also benefitted from further development since the early 1990s providing an additional stimulus for take up (detailed in Section VII). The development of applications of VR DES is the final entry in this categorization. An exploration of the key papers in the aforementioned areas is presented in the following section.

\section{VIRTUAL FACTORY: A SMART FACTORY IN WAITING?}

The rise of the Virtual Factory paradigm has been noted in a wide range of research works, not just those with focus on simulation. This section looks at this paradigm and notes that many of its aims encourage the use of VR DES. In addition, the "Smart Factory" proposed as part of industry 4.0 may take DES VR integration to a new level.

A definition of the Virtual Factory concept has been given by Jain et al. [29] as an "integrated simulation model of major subsystems in a factory that considers the factory as a whole and provides an advanced decision support capability." DES is seen by Jain et al. [29] as a core component of a holistic model of the factory where DES enables an integrated view encompassing all major subsystems to be formed. The Virtual Factory concept is a major driver for the move toward VR and DES integration. As far back as the late 1990s, the potential of VR to add value and help enable the virtual factory concept has been speculated on. Kelsick and Vance [6] postulated one of the initial models for VR and DES integration in their Virtual Factory work. A fundamental aspect of the Virtual Factory is virtual manufacturing, whereby the process of manufacturing is simulated from product design to final production; each stage of the production process is simulated and explored in a VR setting [30].

Tolio et al. [31] develop the concept of the Virtual Factory further noting that "coevolution of products, processes, and production systems," where all three entities evolve concurrently, is a challenge faced by many organizations. Interoperation of the plethora of digital tools that support this concept is essential as each tool tends to implement its own methodology. Tolio et al. [31] illustrate this issue. No more is this the case than in the integration of VR and DES. Tolio et al. [31] stress the need for a common data model, whereby all digitally mapped objects within a factory environment are referred to in a consistent way.

The interoperability of the Virtual Factory is also the concern of Xu et al. [32] who identify three levels of interoperability: the data level, service level, and process level. In order to address interoperability, $\mathrm{Xu}$ et al. [32] document a number of semantic languages and research project outputs that aim to facilitate the communication between subsystems that compose the three layers.

In later work, Jain and Shao [33] note the increasing production and availability of manufacturing data. They make the case for the revision of the Virtual Factory concept to utilize repositories of Big Data fed by the latest production line equipment and factory-based information systems. Data Analytics is central to the enablement of the Virtual Factory in the opinion of Jain and Shao [33], with modeling and simulation essential tools to leverage and make sense of the data available. In the opinion of Jain and Shao [33], the Virtual Factory is, and should be, "a VR representation" for a factory, with 3-D environments and visualization essential for understanding and knowledge share [33]. A framework for the Virtual Factory addressing its data exchange challenges is put forward by Kádár et al. [34] and will be discussed in greater detail in the following section.

Launched in 2011 as a research alliance formed at the behest of the German Government, industry 4.0 has been referred to in literature as the fourth industrial revolution (see [80]). Under Industry 4.0, advances in technologies ranging from cyberphysical systems (CPS) to the Internet of Things, Big Data, and Cloud technologies have been melded together into a comprehensive research agenda for the future of manufacturing. In a similar vein, the Industrial Internet is a consortium formed from organizations such as General Electric, IBM, and Cisco Systems [81], which also set an agenda for the structured research into enabling technologies for, among other sectors, manufacturing. Promising a step change in the way factories operate, both initiatives give mention to the role of simulation. The Smart Factory for some is the manifestation of the much trailed Industry 4.0 initiative and perhaps the practical implementation of the virtual factory concept. Incorporating elements of self-organization and the latest advances in CPS smart factories are an attempt to realize agile production systems to satisfy fast changing consumer markets [87]. Of particular interest to the operation of smart factories is the ability to visualize the end to end operation of production facilities and their related supply chains [80]. Posada et al. [85] elaborate on the value and role of visualization to this paradigm citing industrial use case examples such as realtime resource usage, optimized decision making based on live 
TABLE I

EVOLUTION OF FACTORIES: FrOM TRADITIONAL TO SMART

\begin{tabular}{|c|c|c|}
\hline Factory Evolution & Features & Data use in the decision cycle \\
\hline Traditional Factory & $\begin{array}{l}\text { - Ad-hoc setup of } \\
\text { decisions }\end{array}$ & - Manual from ERP \\
\hline Tools Used & $\begin{array}{l}\cdot \text { Heterogeneous } \\
\text { disparate toolsets }\end{array}$ & - Decision cycle: $<$ one month \\
\hline - Lean & $\begin{array}{l}\text { - Not connected to the } \\
\text { factory floor }\end{array}$ & - Action at factory level \\
\hline $\begin{array}{l}\text { - IDEF } \\
\text { - Statistical analysis } \\
\text { - Spreadsheets } \\
\text { - Paper based tools }\end{array}$ & & \\
\hline Virtual Factory & $\begin{array}{l}\text { - Offline/partially } \\
\text { connected }\end{array}$ & $\begin{array}{l}\text { - Creation of virtual factory } \\
\text { using data }\end{array}$ \\
\hline Tools Used & $\begin{array}{l}\text { - Limited real-time } \\
\text { connected systems }\end{array}$ & - Decision cycle: $<$ one day \\
\hline $\begin{array}{l}\cdot \text { DES } \\
\cdot 3 \mathrm{D} \\
\cdot \text { Agent based } \\
\text { - Physics engine } \\
\text { - Soft computing } \\
\text { techniques }\end{array}$ & - Homogeneous modeling & - Action at machine level \\
\hline Smart Factory & $\begin{array}{l}\text { - Near real-time system } \\
\text { connectivity }\end{array}$ & $\begin{array}{l}\text { - Low latency data driven } \\
\text { decisions }\end{array}$ \\
\hline Tools Used & $\begin{array}{l}\text { - All systems } \\
\text { interconnected inside } \\
\text { and outside the factory }\end{array}$ & - Decision cycle: $<$ seconds \\
\hline $\begin{array}{l}\text { - DES } \\
\text { - Immersive 3-D } \\
\text { - Agent based } \\
\text { - Physics engine } \\
\text { - Mixed reality } \\
\text { - Soft computing } \\
\text { techniques }\end{array}$ & $\begin{array}{l}\text { - Heterogeneous CPS } \\
\text { - Semiautonomous }\end{array}$ & - Action at product level \\
\hline
\end{tabular}

production data, safe robot and human worker interactions, and new production line planning. One particular argument is that the real-time integration between VR DES would be essential for the visualization of smart factory operations. In the next section, the delivery of this need is examined in more detail. Table I outlines the evolution of the factory from the traditional factory with its roots in the 1970s-1980s, where the supporting systems are heterogeneous, disconnected, and data analysis is largely a manual operation with the decision cycle which may be measured in months.

The Virtual factory creates a step change in that it utilizes simulation modeling software such as DES and 3-D representations along with interlinked "intelligent software" to aid the analysis of data and aid the decision-making process. The visualization provided by DES and 3D representations is valuable as "what if" scenarios may be created and tested in a matter of hours offering a real advantage over disparate manual approaches. The virtual factory does not fully encompass the technologies available today, factory systems are not fully interlinked, and real-time or near to real-time data analysis is difficult if not impossible to achieve. The smart factory finally realizes the interconnectivity promised at the start of the Internet age. Full interconnectivity delivers decision support and data analysis in real time. Decision outcomes can be visualized in 3-D utilizing mixed reality allowing users to view DES simulations overlaid

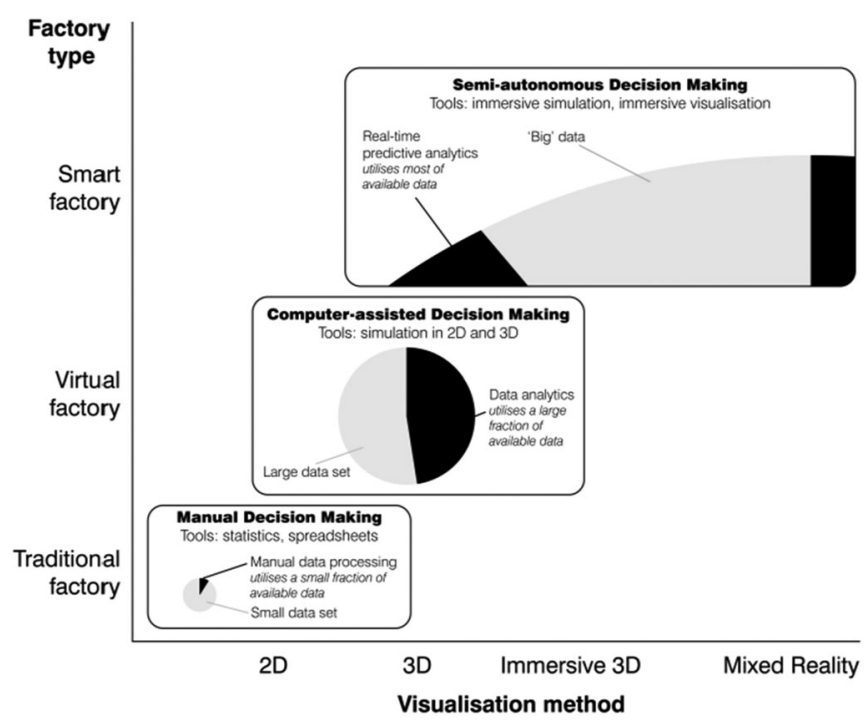

Fig. 5. Factory types and data visualization methods.

on the real-world view as they walk around a factory. The smart factory vision also allows for semiautonomous operation of the factory; decisions selected in DES can be automatically applied to factory floor machines.

The relationship between factory type and appropriate data visualization method is illustrated in Fig. 5. In Fig. 5, it can be seen that in the case of the traditional factory, the availability of data and the means to process it was comparatively limited. This relationship is almost completely inverted in the smart factory in that although a factory production line may provide "Big Data" this is now within the processing range of modern computing and when coupled with VR DES in a mixed reality setting, it can be presented in an interactive way that is accessible for all decision makers within the organization. Combined with predictive analytics, it is VR DES that provides the potential for near to real-time context-related scenario-based interaction with both data and models that has until this point not been fully realized.

\section{Virtual REALity and DiscRete EVENT Simulation REAL-TIME INTEGRATION}

The need for real-time or near to real-time integration and operation of VR DES is clear when considering the virtual or smart factory concepts detailed in the preceding section. It is only when a "live" interactive visualization of production line operations can be presented that any modern factory concept can be considered truly digital.

This acceptance of VR is echoed by Choi et al. [35] who note the increasing prevalence of VR use in manufacturing applications in recent years, identifying the availability of Big Data in manufacturing and the increasing maturity of VR technologies as drivers for the uptake. Although not the primary subject of their research, many of the works Choi et al. [35] cite involve the use of simulation in combination with VR, suggesting an increase in the combined use of these two software tool sets. 
Bijl and Boer [36] note that 3-D visualization is an increasingly popular feature of many simulation software packages, but note that the visualization engines provided often lack the features and sophistication of those provided by games consoles (and other game-focused computer hardware). Bijl and Boer [36] investigated whether the realism of 3-D visualization can be improved and even if it is necessary.

In the opinion of Bijl and Boer [36], the greater the realism provided by a manufacturing simulation, the better the understanding of the subject matter by users and the greater flexibility provided for discussion and analysis of the finer points inherent in the model and exposed by it.

One of the ways to achieve 3-D simulation concurrency with the simulation is via network connections between separate simulation and 3-D software (also allowing remote processing of, and access to, animation or simulations); in addition, a database of state changes can be recorded for a simulation run (especially valid for DES simulations with their real-time decision points and branching logic) [36]. This work, although hinting at interactivity, does fall short of providing a totally immersive interactive environment for full DES model exploration.

Ren and Guan [37] make a contribution to real-time DES use in their case study the construction of a concrete dam. Ghani et al. [38], [39] provide a methodology for Virtual Engineering (VE) and DES combined use, utilizing XML and a normalization schema for model data exchange. Although VE mainly concentrates on the use and manipulation of 3-D CAD models, the integration approach detailed by Ghani et al. [38], [39] could be applied to DES and VR. The possibility to change simulation parameters while a simulation is running via an AR environment is the subject that is explored by Dorozhkin et al. [40]. Dorozhkin et al. [40] were able to achieve temporally coupled concurrent simulation allowing users to interactively start and stop the simulation and change parameters such as inserting new time steps [40]. Dorozhkin et al. [40] also noted that the VR application did slow down over the time it was in use, and their next stage of research was to work toward near real-time operation of the combined system.

The potential interoperability issues between software components that comprise VR systems and DES software have been highlighted by Tolio et al. [31] and Xu et al. [32]. The conclusion of both works was to suggest that there needs to be an agreed formalism for object description and data interchange. One such attempt at such a framework for interoperation has been put forward by Kádár et al. [34] with their virtual factory framework. The framework put forward by Kádár et al. [34] is composed of three layers, encompassing digital factory tools (such as simulation and VR software), a data and knowledge "management decision" layer and a data repository layer [the organization's data store(s)]. Underlying this framework is the virtual factory data model utilizing a semantically described data interchange standard based on web ontology language (compliant with resource definition format (RDF) XML) [34]. RDF query language (SPARQL) is used to query the data stores within this framework. An example is given in this work of the linkage with a 3-D VR collaborative environment, although no details are provided on the speed and performance of the system. Work in a similar vein is exemplified by Akhavian and Behzadan [41] who develop a system to collect data in real time and display it in terms of a 3-D visualization while updating a DES model. A dynamic data-driven application simulation (DDDAS) is the subject of this work, describing the evolving conditions encountered at a construction site. In this case, the DDDAS framework is composed of modules for data collection data classification and analysis and what-if analysis, allowing real-time simulation and analysis to be conducted. Akhavian and Behzadan [41] stress that such a system still requires a "human in the loop" to make decisions and combine multiple scenarios to arrive a particular optimal solution. One particular feature of the 3-D visualization is the inclusion of preprocessed animation along with real-time animation, VR, DES, and mixed reality.

The work of Hamid et al. [42] identifies three types of VR systems: nonimmersive VR, semiimmersive VR, and fully immersive VR. According to Hamid et al. [42], lower immersion types of VR are usually experienced through monitors or a bank of monitors, whereas fully immersive environments may make use of headsets or CAVE-type environments. According to Nielebock et al. [43], the term mixed simulation is used to refer to a combination of DES and VR. For Milgram and Kishino [44], mixed reality can be thought of as a subset of VR. Mixed reality is a combination real world with computer graphics whose state may be expressed at appoint on a virtuality continuum from the real-world environment at one end to a totally artificial environment at the other [44]. Along that continuum, the concept of augmented reality (AR) may be found. AR is the process of overlaying animations and graphics on actual scenes in real time. Ong et al. [45] found that there were certain requirements of an AR system for use in a manufacturing setting such as the need for convenient forms of interaction with prototypes modeled in such a system (hands free system interaction) and the need for systems to be compact and portable. The use of AR has also been the subject of research in combination with DES. Most commonly, AR can be viewed though headset devices. Behzadan et al. [46] provide an example of AR and DES used in the construction industry. Behzadan et al. [46] note the unique ability of AR to overlay CAD animations of construction equipment such as cranes over building site views in real time. Behzadan et al. [46] also note that it is important that sensors such as head trackers and GPS systems need to communicate with AR in real time for the system to be fully functional. A further exploration of the integration of real-time data in DES can be found in [41] and [47].

Another proponent of DES and AR integrated use is Chen and Huang [48]. In this research, AR is used to apply a live connected real-world image as the background to a model of transport operations in a construction site. Back et al. [49] offer an AR-based factory monitoring and control system that allows for the remote administration of shop floor equipment. The environment provided by Back et al. [49] is also capable of use with simulation tools to model certain operations before they are enacted in the factory.

It is likely that real-time visualization of DES models, superimposed on an actual production line when viewed by a user with a head-mounted display (HMD), will be made possible 
with VR DES. It must be noted that real-time use of data streams will be challenging; such data must be subject to filtering for noise and errors, and it is, therefore, likely that discrete timestamped datasets will be used for the creation of DES models in the real-time viewing mode. In essence, the real innovation, encompassed by visions such as "Smart Factory" within industry 4.0 , is the collection and analysis of production line sensor data for use in near to real-time decision making and real-time updating of factory floor machines directly from scenarios facilitated and evaluated through DES. This vision does of course provoke the question of how DES model validation will change with the use of VR and in a future smart/brilliant factory context of "press button" instant implementation of production management decisions.

\section{VALIDATION AND VERIFICATION OF DiscRETE EVENT Simulation Models With ViRTUAL REALiTy}

The most important ingredient in DES validation is a set of robust evaluation criteria. It is put by Robinson [88] that it is not possible to prove a simulation model has $100 \%$ validity in the real world. Typically, most organizations will plan out changes with a combination of software, paper-based assets, and physical prototypes. The DES model may be viewed from different angles. Worker movements on the factory floor when viewed in three dimensions can highlight potential clashes and bottlenecks that would be experienced in real life. It is this concurrent mode of operation that is the goal of VR DES use. In such a scenario, a user wearing a headset will be able to view the running DES model superimposed onto the production line, allowing the user to interact with the model in real time, making decisions based on the outcome of what if experiments. Table II lists a number of common simulation model validation techniques and the role that VR may play.

Customer engagement in the product design and production stages is an additional aim of VR DES. In the case of GE, the product development process introduces new concepts as minimum viable products taking the form of "prototypes, interactions, and engagements at market scale"; the resulting information gained in this way is then processed to form metrics for the further development of the product [89]. Such metrics are an important set of criteria for DES model validation where the manufacturability of the product and considerations as to the modifications required on the production line that may be required are taken into account in the validation process. Being able to visualize not just the product but the manufacturing process, in a "fly though" manner, can have a dramatic impact on engaging customers and confidence building especially in business to business and supply chain sales situations. Such qualitative evaluations from customers can help to cement relationships and build confidence in a manufacturer's abilities and competence.

In time, it may also be possible to retrieve timestamped data in near to real time from machines, run a DES simulation, and automatically translate validated findings into actions on production line machinery. This is the vision that many experts in the DES field are working toward.
TABLE II

MODEL VALIDATION AND VR DES

\begin{tabular}{|c|c|c|}
\hline $\begin{array}{l}\text { Validation } \\
\text { Technique }\end{array}$ & $\begin{array}{c}\text { Potential Role of } \\
\text { VR }\end{array}$ & Example \\
\hline $\begin{array}{l}\text { Black Box } \\
\text { Validation }\end{array}$ & $\begin{array}{l}\text { Simulation overlaid } \\
\text { on real-world view } \\
\text { with AR }\end{array}$ & $\begin{array}{l}\text { The ability to overlay a simulation } \\
\text { on a real-life production line can } \\
\text { help to validate poorly understood } \\
\text { phenomena and aid the } \\
\text { rectification of bottlenecks }\end{array}$ \\
\hline Solution Validation & $\begin{array}{l}\text { Manipulation of DES } \\
\text { models in real time } \\
\text { based on real-world } \\
\text { observations } \\
\text { (in-process } \\
\text { simulation model } \\
\text { changes) }\end{array}$ & $\begin{array}{l}\text { Solutions to manufacturing } \\
\text { problems can be explored in } \\
\text { real-time and obvious } \\
\text { problems/bottlenecks spotted by } \\
\text { superimposing new layouts in } \\
\text { DES on a real shop floor without } \\
\text { the potential cost and risk of } \\
\text { physical implementation }\end{array}$ \\
\hline $\begin{array}{l}\text { Experimentation } \\
\text { Validation }\end{array}$ & $\begin{array}{l}\text { Simulation overlaid } \\
\text { on real-world view } \\
\text { with AR }\end{array}$ & $\begin{array}{l}\text { Comparing the results of what-if } \\
\text { experiments in DES with reality is } \\
\text { much easier when the simulation } \\
\text { view is overlaid on the working } \\
\text { production line (with a } \\
\text { technology such as AR) }\end{array}$ \\
\hline Data Validation & $\begin{array}{l}\text { Real-time in vision } \\
\text { comparison of data } \\
\text { produced with DES } \\
\text { and that registered on } \\
\text { production line } \\
\text { machines }\end{array}$ & $\begin{array}{l}\text { The data being reported by } \\
\text { modeled machines in DES may } \\
\text { be compared in real time to that } \\
\text { reported by actual machines on } \\
\text { the production line (without the } \\
\text { need to physically link the DES } \\
\text { model to the production line) }\end{array}$ \\
\hline
\end{tabular}

\section{Communication Protocols Between ViRtual REALITY AND DisCRETE EVENT SIMULATION}

With the need for VR DES in the visualization of the modern factory established, it could be assumed that a comprehensive set of standards has already been decided on. This, however, is not the case as the existence of a preferred method of communication between VR and DES has yet to be established in research. An initial contribution by Casas et al. [50] puts forward a simulation model representation based on specification and description language. This model is then transformed into an XML description for transmission to the VR application. Sawhney et al. [51] investigate the use of virtual reality modeling language with DES to describe 3-D objects and their animation in their work concentrating on education within the construction industry (developing courses to teach construction processes).

Although not concerning DES-type model simulation, the research of Gajananan et al. [52] introduces scenario markup language (SML). This language aims to describe traffic scenarios for use in a driving simulator linked to a 3-D VR environment. Again, the SML language (based on XML) descriptions formalize a simulation model for transformation and enacting in a separate application. Radkowski and Hilus [53] investigate the use of unified modeling language to describe DES control models to a level suitable for interpretation by VR applications. $\mathrm{Xu}$ et al. [32] provide an overview of semantics and languages for use in the virtual factory and potentially for linking VR DES to wider factory systems. Kádár et al. [34] also propose an ontology-based framework for VR DES combined operation in a factory environment.

In a novel approach, Rossmann et al. [54] utilize a graphbased database containing graphs based on the Petri net 
formalization to act as a way of combining DES and a 3-D animation environment. In this example, DES is used to control the simulation with the graph formalizations used to enact the control instructions in the 3-D environment. These works may contribute to the foundation of semantic interoperability between VR and DES in the future. If there are still challenges remaining in the efficient linking of VR and DES, then it is also true that research scope still exists in the production of immersive DES models. This specific challenge is addressed in the following section.

\section{DESIGNING AND DEVELOPING IMMERSIVE DiSCRETE EVENT SiMULATION}

One of the major challenges in developing DES models that are immersive and expressive in a VR environment is the ability to collect enough data points to produce a realistic rendering of a subject. The work of Lindskog et al. [55] investigates the use of 3-D laser scanning as a way of efficiently capturing a visualization of a manufacturing facility. Such point cloud models, produced by laser scanning, can add extra layers of detail to a DES model drawing in a wider non-DES audience to final rendered models [55]. Lindskog et al. [55] also acknowledge the current difficulties of importing point cloud models into DES as opposed to the use of more standard CAD descriptions [55]. Use of VR CAVE viewing environment for DES VR combinations has been explored by Gurevich and Sacks [48]. In this work, a virtual construction site was developed so that the decisionmaking behavior of study participants could be evaluated. The study involved the design of experiments to ascertain the value of the VR DES system in practice and as such acts as a valuable set of pointers for the design of future DES VR systems [56], [57].

The use of agent technologies in a DES system is explored by Kádár et al. [58]. In this work, agent-based technologies are utilized for decision making and communication purposes in a DES simulation environment. Although this work does not attempt to integrate VR as well, it does point to the possibility of agent technologies to provide intelligent VR DES capable of active support for decision making and scenario building. In [41], the use of sensor data streams in DES is explored. In particular, the use of GPS and RFID sensors as tracking devices for use with simulation-based systems is proposed.

In addition to the Oculus system, another HMD device gaining interest is Microsoft HoloLens [90]. This device has been designed as an AR viewing platform providing a mixed reality view of the real world with superimposed active graphics [90]. The AR graphics are designed to appear holographic in nature [91]. The makers Microsoft are currently working with car company Volvo to utilize HoloLens in the development of customer experience applications allowing users to experience and configure new cars [91].

The work of Hamid et al. [42] with their VR system types also defines appropriate input devices. For nonimmersive VR, these are the peripherals most typically available with a computer such as mice, keyboards, joysticks, and trackballs. With fully immersive VR, gloves and voice commands may well be used
[42]. The use of devices such as Microsoft Kinect opens up new ways of interaction; with its use of marker-less tracking body movements of users may be interpreted as interactions with a VR system. In addition, Cho et al. [59] detail a range of interaction devices that are suitable for use in VR applications. Navigating multiple dimensions in VR presents problems, and Cho et al. [59] provide a new hybrid finger ball allowing users to interact with both 2-D and 3-D visualizations with the same device. In addition, Cho et al. [59] detail a range of interaction devices that are suitable for use in VR applications.

Skripcak et al. [60] provide details on human-computer interface considerations for use in the administration of industrial plant monitoring activities. In this work, Skripcak et al. [60] make reference to the use of motion tracking sensors such as Microsoft Kinect and Asus Xtion that are able to recognize and interpret human gestures. In addition to motion tracking, the use of smartphone functionality as mode of interaction is examined along with more unconventional methods such as brain based interaction with systems via an electroencephalogram sensor.

For tracking human motion in an immersive environment, the accepted "gold standard" is the multicamera marker-based solutions such as those offered by Qualisys, Vicon, and OptiTrack [61]. Due to their high cost, these are normally paired with dedicated CAVE systems. With the advent of affordable VR solutions such as Oculus Rift, HMD, increasing numbers of more affordable tracking solutions are being put on the market. Oculus and its controller Oculus Touch relies on infrared tracking on a small number of cameras [62]. Another approach uses wireless electromagnetic sensing, which addresses the occlusion problems inherent in camera-based systems [63]. Another approach is by attaching inertial measurement units at body joints, exemplified at the high end by Xsens [64] and at the lower end by Perception Neuron [65].

Most systems have difficulty tracking fingers of a human user. Leap Motion sensor uses stereoscopic IR camera to capture and infer hand and finger motion, but its usable space is limited [66]. VR is particularly suitable for new interaction techniques, such kinaesthetic interaction based on the detection of body gestures (e.g., with Microsoft Kinect) or finger gestures (e.g., with Leap Motion) [92]. A pairing of Leap Motion with Oculus HMD has shown very promising results in a number of research works [93], [94] allowing some of the earliest prototypes of fingerbased immersive interfaces to be created. In their latest form, the combination of Oculus, Kinect, and Leap Motion hardware is shown to be a viable means of interacting with engineering and construction environments [95]. In another approach, Myo sensors strapped on the operator's forearm captures electrical signals given out by forearm muscles, enabling it to sense hand attitude in VR scenes [67].

In the compilation of this research, a number of advantages and limitations in the use of VR DES have been identified; these are outlined in Table III.

From Table III, it is difficult to overemphasize the positive impact a VR DES model can have in its ability to communicate complex manufacturing scenarios to varied audiences. At present though, this offering does present a number of limitations. These take the form of high production costs, with a major 
TABLE III

ADVANTAGES AND LIMITATIONS OF VR DES

\begin{tabular}{|c|c|}
\hline \multicolumn{2}{|r|}{ Advantages of VR DES } \\
\hline • & $\begin{array}{l}\text { VR DES makes it easier to view the effects of complex data } \\
\text { sets and interactions in DES models }\end{array}$ \\
\hline • & $\begin{array}{l}\text { Ability to capture and compare the virtual and physical state } \\
\text { of objects }\end{array}$ \\
\hline • & $\begin{array}{l}\text { Use of the DES model as an AR overlay to a production line } \\
\text { can be useful in highlighting bottlenecks and problems }\end{array}$ \\
\hline • & $\begin{array}{l}\text { A 3-D representation of a model can help in communicating } \\
\text { changes to both internal and external to the organization }\end{array}$ \\
\hline • & $\begin{array}{l}\text { Additional views and navigation of a model not viewable } \\
\text { with 2-D and in some cases difficult to see with } \\
\text { screen-based 3-D representations are possible with VR DES } \\
\text { used with head mounted devices and AR }\end{array}$ \\
\hline • & $\begin{array}{l}\text { DES is capable of integration with other factory based } \\
\text { systems and may act as a context provider in the VR } \\
\text { visualization of the outputs provided by 3rd party } \\
\text { applications }\end{array}$ \\
\hline \multicolumn{2}{|r|}{ Limitations of VR DES } \\
\hline • & High cost of model production \\
\hline • & $\begin{array}{l}\text { DES model building is a time-consuming process, the need } \\
\text { to capture additional dimensions add to this }\end{array}$ \\
\hline • & $\begin{array}{l}\text { Expert knowledge of modeling and the process/facility to be } \\
\text { modeled is required }\end{array}$ \\
\hline • & $\begin{array}{l}\text { Human interactions and gestures are difficult capture and } \\
\text { use in current VR DES applications (though this challenge } \\
\text { is subject to ongoing research) }\end{array}$ \\
\hline • & $\begin{array}{l}\text { Real-time data streams are difficult to integrate into DES } \\
\text { (with and without VR) }\end{array}$ \\
\hline • & Some reports of motion sickness with HMD use \\
\hline
\end{tabular}

drawback being the limited ability for human VR DES interactivity. The work of Araullo et al. [96] report motion sickness experienced by some users of VR games, while this is a potential issue at the moment it is thought that improved graphics and reduced latency in rendering (in relation to the real world) will be available in future versions of VR hardware and software. In the following two sections, it will be seen how some of the identified advantages and limitations of VR and DES are manifest and may be addressed in future research.

\section{APPLiCATIONS OF VIRTUAL REALITY AND DisCRETE EVENT SiMULATION}

Practical applications of VR DES have been available for some years, although their use up until this point has been limited. Advances in technology have in part triggered a renewed interest in this area, which is reflected in the available research. In one of the first publications to recognize the value and importance of VR DES for manufacturing, Sacco et al. [68] pose the task of designing a new factory and look at what a combination of such tools can offer personnel involved in the architecting of such a facility. This work also mentions the sequential use of VR and DES followed by the implementation of the Virtual Factory paradigm as a way of managing the day to day operation of the facility [68]. Another early work in this area is provided by Bick et al. [69] who also investigate the use of VR DES to simulate a Robot Welding Cell within a manufacturing plant. This is also the subject for the contemporary research of Orady et al. [70]. Vasudevan and Son [71] propose a novel use of VR DES in the planning of evacuation safety in a manufacturing facility; the research aims to find a balance between productivity and the provision of safe egress from the facility in emergency situations.

According to Hamid et al. [42], applications of VR in manufacturing design broadly divide into two categories, those concentrated on aiding product design and applications used for virtual prototyping; within manufacturing processes, the three categories of machining, assembly, and inspection are defined for VR applications, and in operations management, additional three categories are planning, simulation, and training [42].

The work of Alves et al. [72] explores the subjects transport and logistics systems involved in the routing of resources. A combination of VR and DES is proposed and then developed for the modeling of a forest management scenario. This research in its current form does not extend to the simulation of the processing of felled timber within a factory, although Alves et al. [72] aim to explore this in future work. VR and DES use examples may also be found: in the work of Dong et al. [73] who examine the visual simulation of the construction of an underground transformer substation; in the area of automotive assembly [74]; and training on a manufacturing production line [75].

The use of AR and DES within the construction industry is exemplified by the work of Behzadan et al. [46]; utilizing the AR's advantage of VR in that computer generated images can be overlaid on an actual scene in real time, promoting mobile on site use of such a system (as detailed in Section V). In another case study involving the construction industry, Kamat and Martinez [76]-[78] investigate 3-D visualization in conjunction with DES to model fluid materials.

Kelsick et al. [13] describe the use of a CAVE type VR system in the development of a factory simulation. The VRFactory prototype allows the user to view the VR simulation through a headset and make a number of interactions with the system through a menu system. In further work, Kelsick et al. [13] aim to develop the system further to allow changes to the simulation to be made from within the VR environment. For further examples of VR applied to a range of manufacturing uses, see [35], in which Choi et al. provide a comprehensive summary of the key works to date. As outlined in this section, the growth in interest in VR and DES applications within industry suggests a promising future. It must be noted that much scope still remains in developing VR DES as the de facto visualization for decision making and control in the "dashboard" of the digital factory.

\section{FutURe DeVELOPMENTS}

It is clear that there is a future for VR DES systems as 3-D visualizations are the natural progression from 2-D DES. In line with smart factory visions, new manufacturing concepts will also benefit from VR DES. Mourtzis et al. [79] make the case for distributed collaborative product development and the use of DES and VR as a vehicle to achieve this. With developments in the technology and a decreasing price point, this approach may become ubiquitous in manufacturing. Mourtzis et al. [79] also make the case for the possibility of VR DES systems to be 
able to capture knowledge and exhibit decision making/support ability through computational intelligence approaches and agent technologies (with agents utilized to provide data locating and filtering services). The inclusion of intelligence in VR DES systems may well be furthered by examining the approach of Kádár et al. [58] who may provide a template for future research in this direction. Such learning systems would further promote the take up of such technology in industry.

The shape and form of AR DES ten years from now will be influenced by the merging of simulation functionality. It is envisaged that the functionality provided by agent-based simulation [97] may well be integrated into DES, allowing for intelligent semiautonomous problem space exploration. With the increasing sophistication of VR DES implementations, there will also be a need for greater realism and accuracy in the visualized simulations. In the same way, there may be a role for the physics engine within DES for the provision of more accurate rendering of machinery as there already is within VR [98]. It is also possible that agent, DES, and physics engine functionalities may in the future be provided as interoperable services to be combined by the user to provide new hybrid applications. In the VR hardware area, continuing developments in miniaturization and lightweighting will increase the wearability of head-mounted devices. Latency inherent in current VR DES implementations will also disappear as real-time rendering becomes possible due to the continuing rise in computing power and more sophisticated graphics rendering engines. A current limitation of VR DES is the difficulty of human gesture recognition for the control of interactions with simulation models. Work toward addressing this limitation is evidenced by Prahbu et al. [99] who examine the use of low-cost sensors such as Microsoft Kinect to capture human motion in an industrial work-based setting. Such investigations could hold the key to more natural VR DES interactions in future iterations of this technology.

At this point, it is interesting to revisit the Industry 4.0 and industrial internet initiatives with their focus on simulation and visualization for digital manufacturing (in the "Smart/Brilliant" factory). A number of active research topics for VR DES in manufacturing still exist.

1) Near to real-time DES.

2) Lower latency image processing for VR and mixed reality.

3) DES as a service.

4) Gesture recognition software and hardware for VR and mixed reality.

5) New graphical representations of Big Data in combination with DES for mixed reality viewing.

6) Shortened cycle model building with DES.

7) Semi-autonomous problem solving with DES.

8) Linking DES to real-time data streams and Big Data sets.

Among the most pressing areas for investigation is the linkage of DES with real-time data streams and Big Data. This is likely to involve timestamping of data and the creation of scenarios based on near to real-time "snapshots" of data. It is certain that research in data analytics will need to take account of the discrete nature of DES in order to harness its decision support capability and potential future role within autonomous decision making systems. In addition, DES VR may provide the visual audit trail for implemented scenarios including the provenance of data analyzed and utilized in their inception. Another active area of research is safe use of VR and mixed reality exemplified in the work of Lebeck et al. [100] who explore ways of rendering graphics in sympathy to potential collision hazards for humans navigating real environments with an augmented view.

The VR DES combination fits within the vision for internet connected manufacturing where CPS may be visualized and interacted with in real time. This role for VR DES would allow for virtual scenarios to be automatically enacted on the shop floor, such as altered machine settings and setups along with altered settings for production line robots. In the same way, network aware sensors, capable of exchanging information with each other and ascertaining their own position within a manufacturing process, will be more prevalent and the decreasing price point of sensors in general will see them included in greater numbers within production line machinery, measuring parameters previously not captured due to expense and lack of processing power. The relative ease of capture, processing, and analysis of sensor data will mean that the autonomously generated visualization of production lines for real-time "what if" scenario building may well become the norm.

The increasing sophistication and availability of interaction hardware for VR means that such devices are now much less of a potential stumbling block to adoption. It is certain that the VR interaction devices identified by Cho et al. [59] will be developed further (in addition to the new devices appearing on the market almost every month). Compatible with the aforementioned initiatives, the concept of Cloud Manufacturing [82] makes the advance beyond cloud computing to include the production line as an internet linked service (alongside Software, Hardware, infrastructure, and Platform services). By its very nature, VR DES may be servitized in its mode of operation allowing geographically dispersed users to collaborate in a project; it also allows the possibility to "hire out" VR DES functionality, at a software level, for a particular amount of time. In linking together, VR DES and the internet-connected production line will require standardization in communication protocols; the use of ontology and semantics as outlined in the work by $\mathrm{Xu}$ et al. [32] and Kádár et al. [34] are two contributions toward this interoperability goal.

The vision outlined by some research works is to involve the consumer within the product design process (see [83]). Going beyond the predefined selection of options in a sales environment, enabled by mass customization, mass personalization scenarios may involve customers being able to change the look and functionality of products within the design stage (see [84]). Such parameters would then need to form part of the decision making at the production line level; VR DES provides such a platform for scenario building, analysis, and enactment triggered by the dynamic inclusion of such parameters. It is likely that the field of VR DES research, contributed to by Kelsick et al. [6], [13], Akpan and Brooks [1], and Page and Smith [5] will now find new impetus by not just the refinement of technologies but new initiatives as outlined in this section that promote interconnectedness and near to real-time integration of production line data (as outlined by Akhavian and Behzadan [41]). 


\section{CONCLUSION}

The use of VR and DES in combination makes for a compelling case for uptake in the digital manufacturing area. Technological developments in VR DES interoperability along with the introduction of increasingly sophisticated interaction devices mean that the future of factory design and layout, product and service development, and industrial plant decision making and control may all benefit from VR-based simulation systems.

The introduction of initiatives such as Industry 4.0 and the Industrial Internet hasten the further development of VR DES as a visualization platform for the development of next-generation internet-linked manufacturing production lines inherent in the delivery of the smart factory. The live interaction with and manipulation of virtual manufacturing scenarios, automatically captured from real life and described semantically, in real time within DES is a realistic goal of VR DES. In combination with machine intelligence, the autonomous enactment of scenarios on the production line is a real possibility in the near future.

It is clear from this research that in the future of VR DES, its interoperability with data providers and production line sensor streams will be key; in this light development in semantic technology and ontology with the aim of mapping sensor networks into a descriptive format readable by DES is paramount. Increasingly product development is being seen as a process where products are developed not just with their use but also their end of life and recycling taken into consideration. In this case, VR DES may be deployed to examine the manufacturability and perhaps remanufacture of such holistically developed products. In terms of outstanding research issues while efforts have been made, especially in the area of semantics, standardization of communication protocols is still an area that requires further work. It is interesting to note the increased sophistication of interaction possible with the latest VR hardware when compared with those available only $10-15$ years ago. This trend will undoubtedly lead to VR devices that are faster lighter and available at even lower price points for integration into a wide variety of applications both in industry and in the home. With a longer term move to fully autonomous production, there will still be a need for the "human in the loop" to make sense of the data and the decisions being made; it is perhaps in this goal that use of VR and DES will fully realize its potential and deliver on the early promise.

\section{REFERENCES}

[1] J. Akpan and R. J. Brooks, "Practitioners' perception of the impacts of virtual reality on discrete-event simulation," in Proc. Winter Simul. Conf., 2005, pp. 1976-198.

[2] G. Fishman, Discrete-Event Simulation: Modeling, Programming, and Analysis. Heidelberg, Germany: Springer, 2013.

[3] G. C. Burdea and P. Coiffet, Virtual Reality Technology, vol. 1. New York, NY, USA: Wiley, 2003.

[4] T. Mazuryk and M. Gervautz, "Virtual reality history, applications, technology and future," Inst. Comput. Graph. Algorithms, Vienna Univ. Technol., Vienna, Austria, Tech. Rep. TR-186 -2-96-06, 1996.

[5] E. H. Page and R. Smith, "Introduction to military training simulation: A guide for discrete event simulationists," in Proc. 30th Winter Simul. Conf., 1998, pp. 53-60.

[6] J. J. Kelsick and J. M. Vance, "The VR factory: Discrete event simulation implemented in a virtual environment," presented at the ASME Design Eng. Tech. Conf./Design Manuf., Atlanta, GA, USA, Sep. 1998.
[7] P. Waurzyniak, "Visualizing manufacturing," Manuf. Eng., vol. 142, no. 6 , p. 41, 2009.

[8] R. Steffan, U. Schull, and T. Kuhlen, "Integration of virtual reality based assembly simulation into CAD/CAM environments," in Proc. 24th Annu. Conf. IEEE Ind. Electron. Soc., 1998, vol. 4, pp. 2535-2537.

[9] M. C. Leu, "CAD model based virtual assembly simulation, planning and training," CIRP Ann., Manuf. Technol., vol. 62, no. 2, pp. 799-822, 2013.

[10] T. Kim, J. Lee, and P. Fishwick, "A two-stage modeling and simulation process for web-based modeling and simulation," ACM Trans. Model. Comput. Simul., vol. 12, no. 3, pp. 230-248, 2002.

[11] P. A. Fishwick, "RUBE: An XML-based architecture for 3D process modeling and model fusion," Proc. SPIE, vol. 4716, pp. 330-335, 2002.

[12] A. P. Waller and J. Ladbrook, "Virtual worlds: Experiencing virtua factories of the future," in Proc. 34th Winter Simul. Conf.: Exploring New Frontiers, 2002, pp. 513-517.

[13] J. Kelsick, J. M. Vance, L. Buhr, and C. Moller, "Discrete event simulation implemented in a virtual environment," J. Mech. Design, vol. 125, no. 3, pp. 428-433, 2003

[14] E. Freund and M. Schluse, "Object oriented discrete event based simulation and control of complex 3D systems," in Proc. IEEE Conf. Robot. Autom. Mechatronics, 2004, vol. 2, pp. 863-868.

[15] Y. Zhong and B. Shirinzadeh, "Virtual factory for manufacturing process visualization," Complexity Int., vol. 12, pp. 1-22, 2005.

[16] W. Dangelmaier, K. Mahajan, D. Huber, and B. Mueck, "A two-tier method for evaluating alternative policies to support interactive analysis of 3D material flow simulations," in Proc. Winter Simul. Conf., 2005, p. 10.

[17] P. Cunha, J. DionÍsio, and E. Henriques, "An architecture to support the manufacturing system design and planning," Int. J. Comput. Integr. Manuf., vol. 16, pp. 605-612, 2003.

[18] A. Lektauers, "A mixed reality framework for visualization and execution of DEVS-based simulation models," in Proc. 19th Eur. Conf. Model. Simul., 2005, pp. 1-4.

[19] S. Robinson, "Discrete-event simulation: From the pioneers to the present, what next?" J. Oper. Res. Soc., vol. 56, no. 6, pp. 619-629, 2005.

[20] S. Nielebock, F. Ortmeier, M. Schumann, and A. Winge, "From discrete event simulation to virtual reality environments," in Computer Safety, Reliability, and Security. Berlin, Germany: Springer, 2012, pp. 508-516.

[21] M. Fumarola, M. Seck, and A. Verbraeck, "An approach for loosely coupled discrete event simulation models and animation components," in Proc. Winter Simul. Conf., 2010, pp. 2161-2170.

[22] P. V. Rekapalli, J. C. Martínez, and V. R. Kamat, "Algorithm for accurate three-dimensional scene graph updates in high-speed animations of previously simulated construction operations," Comput.-Aided Civil Infrastructure Eng., vol. 24, no. 3, pp. 186-198, 2009.

[23] P. V. Rekapalli and J. C. Martinez, "Discrete-event simulation-based virtual reality environments for construction operations: Technology introduction," J. Construction Eng. Manage., vol. 137, no. 3, pp. 214-224, 2010.

[24] P. V. Rekapalli and J. C. Martinez, "Time advance synchronization in concurrent discrete-event simulation and animation of construction operations," presented at the 11th Int. Conf. Civil, Struct., Environ. Eng. Comput., Stirling, U.K., 2007.

[25] P. V. Rekapalli and J. C. Martinez, "Gaming perspective based visual interactive simulation for validation of simulated construction operations," in Proc. Int. Workshop Comput. Civil Eng., 2007, pp. 435-442.

[26] P. V. Rekapalli, "Discrete event simulation based virtual reality environments for construction operations," Ph.D. dissertation, Sch. Civil Eng., Purdue Univ., West Lafayette, IN, USA, 2008.

[27] J. Akpan and R. J. Brooks, "Practitioners' perception of the impacts of virtual reality on discrete-event simulation," in Proc. Winter Simul. Conf., 2005, p. 9.

[28] I. J. Akpan and R. J. Brooks, "Users' perceptions of the relative costs and benefits of 2D and 3D visual displays in discrete-event simulation," Simulation, vol. 88, no. 4, pp. 464-480, 2012.

[29] S. Jain, N. F. Choong, K. M. Aye, and M. Luo, "Virtual factory: An integrated approach to manufacturing systems modeling," Int. J. Oper. Prod. Manage., vol. 21, nos. 5/6, pp. 594-608, 2001.

[30] M. C. F. Souza, M. Sacco, and A. J. V. Porto, "Virtual manufacturing as a way for the factory of the future," J. Intell. Manuf., vol. 17, no. 6, pp. 725-735, 2006.

[31] T. Tolio, M. Sacco, W. Terkaj, and M. Urgo, "Virtual factory: An integrated framework for manufacturing systems design and analysis," Procedia CIRP, vol. 7, pp. 25-30, 2013. 
[32] L. Xu, P. de Vrieze, and L. Wei, "Supporting interoperability of virtual factories," in Collaborative Systems for Smart Networked Environments. Berlin, Germany: Springer, 2014, pp. 510-517.

[33] S. Jain and G. Shao, "Virtual factory revisited for manufacturing data analytics," in Proc. Winter Simul. Conf., 2014, pp. 887-898.

[34] B. Kádár, W. Terkaj, and M. Sacco, "Semantic Virtual Factory supporting interoperable modelling and evaluation of production systems," CIRP Ann., Manuf. Technol., vol. 62, no. 1, pp. 443-446, 2013.

[35] S. Choi, K. Jung, and S. D. Noh, "Virtual reality applications in manufacturing industries: Past research, present findings, and future directions," Concurrent Eng., vol. 23, no. 1, pp. 40-63, 2015.

[36] J. L. Bijl and C. A. Boer, "Advanced 3D visualization for simulation using game technology," in Proc. Winter Simul. Conf., 2011, pp. 2815-2826.

[37] B. Y. Ren and T. Guan, "Research on Real-time interactive simulation for concrete dam construction process based on vega," Appl. Mech. Mater., vol. 256, pp. 2849-2853, 2013.

[38] U. Ghani, R. Monfared, and R. Harrison, "Real time energy consumption analysis for manufacturing systems using integrative virtual and discrete event simulation," Int. J. Energy Eng., vol. 2, no. 3, pp. 69-73, 2012.

[39] U. Ghani, R. Monfared, and R. Harrison, "Integration approach to virtual-driven discrete event simulation for manufacturing systems," Int. J. Comput. Integr. Manuf., vol. 28, no. 8, pp. 1-17, 2015.

[40] D. V. Dorozhkin, J. M. Vance, G. D. Rehn, and M. Lemessi, "Coupling of interactive manufacturing operations simulation and immersive virtual reality," Virtual Reality, vol. 16, no. 1, pp. 15-23, 2012.

[41] R. Akhavian and A. H. Behzadan, "An integrated data collection and analysis framework for remote monitoring and planning of construction operations," Adv. Eng. Informat., vol. 26, no. 4, pp. 749-761, 2012.

[42] N. S. S. Hamid, F. A. Aziz, and A. Azizi, "Virtual reality applications in manufacturing system," in Proc. Sci. Inf. Conf., 2014, pp. 1034-1037.

[43] S. Nielebock, F. Ortmeier, M. Schumann, and A. Winge, "From discrete event simulation to virtual reality environments," in Computer Safety, Reliability, and Security. Berlin, Germany: Springer, 2012, pp. 508-516.

[44] P. Milgram and F. Kishino, "A taxonomy of mixed reality visual displays," IEICE Trans. Inf. Syst., vol. 77, no. 12, pp. 1321-1329, 1994.

[45] S. K. Ong, M. L. Yuan, and A. Y. C. Nee, "Augmented reality applications in manufacturing: A survey," Int. J. Prod. Res., vol. 46, no. 10, pp. 2707-2742, 2008.

[46] A. H. Behzadan, S. Dong, and V. R. Kamat, "Mobile and pervasive construction visualization using outdoor augmented reality," in Mobile and Pervasive Computing in Construction, C. J. Anumba and X. Wang, Eds. Oxford, U.K.: Wiley-Blackwell, 2012, pp. 54-85.

[47] A. H. Behzadan and V. R. Kamat, "Enabling smooth and scalable dynamic 3D visualization of discrete-event construction simulations in outdoor augmented reality," in Proc. 39th Winter Simul. Conf., 2007, pp. 2168-2176.

[48] H. M. Chen and P. H. Huang, "3D AR-based modeling for discrete-event simulation of transport operations in construction," Autom. Construction, vol. 33, pp. 123-136, 2013.

[49] M. Back, "The virtual chocolate factory: Building a real world mixedreality system for industrial collaboration and control," in Proc. IEEE Int. Conf. Multimedia Expo, Jul. 19-23, 2010, pp. 1160-1165.

[50] P. F. Casas, X. Pi, J. Casanovas, and J. Jové, "Definition of virtual reality simulation models using specification and description language diagrams," in Proc. 16th Int. SDL Forum, 2013, pp. 258-274.

[51] A. Sawhney, A. Mund, and J. Koczenasz, "Internet-based interactive construction management learning system," J. Construction Edu., vol. 6, no. 3, pp. 124-138, 2001.

[52] K. Gajananan, A. Nantes, M. Miska, A. Nakasone, and H. Prendinger, "An experimental space for conducting controlled driving behavior studies based on a multiuser networked 3D virtual environment and the scenario markup language," IEEE Trans. Human-Mach. Syst., vol. 43, no. 4, pp. 345-358, Jul. 2013.

[53] R. Radkowski and M. Hilus, "Unified modeling language to enhance the specification of discrete event systems for virtual reality applications," in Proc. ASME World Conf. Innovative Virtual Reality, 2011, pp. 31-40.

[54] J. Rossmann, M. Schluse, and R. Waspe, "Creating hybrid simulation systems using a flexible meta data approach," in Simulation Modeling Methodologies, Technologies and Applications. New York, NY, USA: Springer, 2015, pp. 23-36.

[55] E. Lindskog, J. Berglund, J. Vallhagen, R. Berlin, and B. Johansson, "Combining point cloud technologies with discrete event simulation," in Proc. Winter Simul. Conf., 2012, p. 281.
[56] U. Gurevich and R. Sacks, "Examination of the effects of a KanBIM production control system on subcontractors' task selections in interior works," Autom. Construction, vol. 37, pp. 81-87, 2014.

[57] R. Sacks, U. Gurevich, and B. Belaciano, "Hybrid discrete event simulation and virtual reality experimental setup for construction management research," J. Comput. Civil Eng., vol. 29, no. 1, pp. 04014029-1-04014029-9, 2015

[58] B. Kádár, A. Pfeiffer, and L. Monostori, "Building agent-based systems in a discrete-event simulation environment," in Multi-Agent Systems and Applications IV. Berlin, Germany: Springer, 2005, pp. 595-599.

[59] I. Cho, X. Wang, and Z. J. Wartell, "HyFinBall: A two-handed, hybrid 2D/3D desktop VR interface for multi-dimensional visualization," Proc. SPIE, vol. 9017, p. 90170E, 2014.

[60] T. Skripcak, P. Tanuska, U. Konrad, and N. Schmeisser, "Toward nonconventional human-machine interfaces for supervisory plant process monitoring," IEEE Trans. Human-Mach. Syst., vol. 43, no. 5, pp. 437-450, Sep. 2013.

[61] J. G. Richards, "The measurement of human motion: A comparison of commercially available systems," Human Movement Sci., vol. 18, no. 5, pp. 589-602, 1999.

[62] Oculus Rift. 2015. [Online]. Available: https://www.oculus.com/enus/rift/. Accessed on: Feb. 9, 2016.

[63] Sixense STEM: Wireless Motion Tracking System. 2015. [Online]. Available: http://sixense.com/wireless/. Accessed on Feb. 9, 2016.

[64] Xsens: Inertial Motion Tracking. 2015. [Online]. Available: https://www.xsens.com/products/. Accessed on: Feb. 9, 2016.

[65] Perception Neuron: Inertial Motion Tracking. 2015. Accessed on Feb. 9, 2016. [Online]. Available: https://neuronmocap.com/

[66] Y. Liu and Y. Zhang, "Toward welding robot with human knowledge: A remotely-controlled approach," IEEE Trans. Autom. Sci. Eng., vol. 12, no. 2, pp. 769-774, Apr. 2015.

[67] E. Vogiatzaki and A. Krukowski, "Virtual reality gaming with immersive user interfaces," in Modern Stroke Rehabilitation through e-Health-based Entertainment. New York, NY, USA: Springer, 2016, pp. 195-214.

[68] M. Sacco, S. Mottura, G. Viganò, A. Avai, and C. R. Boër, "Tools for the innovation: Virtual reality and discrete events simulation to build the 2000 factory," in Proc. Int. Conf. Adv. Manuf. Syst. Manuf. Autom., Guangzhou, China, 2000, pp. 19-22.

[69] B. Bick, M. Kampker, G. Starke, and M. Weyrich, "Realistic 3Dvisualisation of manufacturing systems based on data of a discrete event simulation," in Proc. 24th Annu. Conf. IEEE Ind. Electron. Soc., 1998, vol. 4, pp. 2543-2548.

[70] E. A. Orady, T. A. Osman, and C. P. Bailo, "Virtual reality software for robotics and manufacturing cell simulation," Comput. Ind. Eng., vol. 33, no. 1, pp. 87-90, 1997.

[71] K. Vasudevan and Y. J. Son, "Concurrent consideration of evacuation safety and productivity in manufacturing facility planning using multiparadigm simulations," Comput. Ind. Eng., vol. 61, no. 4, pp. 1135-1148, 2011.

[72] G. Alves, J. Roßmann, and R. Wischnewski, "A discrete-eventsimulation approach for logistic systems with real time resource routing and VR integration," World Acad. Sci., Eng. Technol., vol. 58, pp. 821-826, 2009.

[73] W. P. Dong, H. H. Zhu, and X. J. Li, "GIS-based visual simulation of the underground transformer substation construction," in Proc. 6th Int. Conf. Adv. Opt. Mater. Devices, 2008, p. 714311.

[74] F. Lambiase and A. Lambiase, "An integrated approach to the analysis of automotive assembly activities using digital manufacturing tools," Int. J. Internet Manuf. Serv., vol. 1, no. 2, pp. 160-175, 2008.

[75] L. Whitman, V. Madhavan, D. Malzahn, J. Twomey, and K. Krishnan, "Using virtual reality to address competency gaps," in Proc. Amer. Soc. Eng. Edu. Annu. Conf. Expo., 2002, pp. 7.1285.1-7.1285.11.

[76] V. R. Kamat and J. C. Martinez, "Dynamic three-dimensional visualization of fluid construction materials," J. Comput. Civil Eng., vol. 18, no. 3, pp. 237-247, 2004.

[77] V. R. Kamat and J. C. Martinez, "Automated generation of dynamic, operations level virtual construction scenarios," Electron. J. Inf. Technol. Construction, vol. 8, pp. 65-84, 2003.

[78] V. R. Kamat and J. C. Martinez, "Enabling smooth and scalable dynamic 3D visualization of discrete-event construction simulations," in Proc. 33rd Winter Simul. Conf., 2001, pp. 1528-1533.

[79] D. Mourtzis, N. Papakostas, D. Mavrikios, S. Makris, and K. Alexopoulos, "The role of simulation in digital manufacturing: Applications and outlook," Int. J. Comput. Integr. Manuf., vol. 28, no. 1, pp. 3-24, 2015. 
[80] H. Kagermann, J. Helbig, A. Hellinger, and W. Wahlster, "Recommendations for Implementing the Strategic Initiative INDUSTRIE 4.0: Securing the Future of German Manufacturing Industry," Final Report of the Industrie 4.0 Working Group. Forschungsunion. 2013. Accessed on Feb. 9, 2016. [Online]. Available: http://www.acatech.de/fileadmin/user_ upload/Baumstruktur_nach_Website/Acatech/root/de/Material_fuer_ Sonderseiten/Industrie_4.0/Final_report_Industrie_4.0_accessible.pdf

[81] Industrial Internet Consortium. Introduction, 2016. Accessed on Feb. 9, 2016. [Online]. Available: http://www.iiconsortium.org/about-us.htm

[82] X. Xu, "From cloud computing to cloud manufacturing," Robot. Comput.-Integr. Manuf., vol. 28, no. 1, pp. 75-86, 2012.

[83] D. Mourtzis and M. Doukas, "Design and planning of manufacturing networks for mass customisation and personalisation: Challenges and outlook," Procedia CIRP, vol. 19, pp. 1-13, 2014.

[84] D. Wu, D. W. Rosen, L. Wang, and D. Schaefer, "Cloud-based design and manufacturing: A new paradigm in digital manufacturing and design innovation," Comput.-Aided Design, vol. 59, pp. 1-14, 2015.

[85] J. Posada et al., "Visual computing as a key enabling technology for industrie 4.0 and industrial internet," IEEE Comput. Graph. Appl., vol. 35, no. 2, pp. 26-40, Mar./Apr. 2015.

[86] A. Radziwon, A. Bilberg, M. Bogers, and E. S. Madsen, "The smart factory: Exploring adaptive and flexible manufacturing solutions," Procedia Eng., vol. 69, pp.1184-1190, 2014.

[87] T. James, "Smart factories," Eng. Technol., vol. 7, no. 6, pp. 64-67, 2012.

[88] S. Robinson, Simulation: The Practice of Model Development and Use. London, U.K.: Palgrave Macmillan, 2014.

[89] D. Merfeld, "GE is in a startup state of mind," Res. Technol. Manage., vol. 57, no. 6, pp. 26-32, 2014.

[90] H. Chen, A. S. Lee, M. Swift, and J. C. Tang, "3D collaboration method over HoloLens ${ }^{\mathrm{TM}}$ and Skype ${ }^{\mathrm{TM}}$ end points," in Proc. 3rd Int. Workshop o Immersive Media Experiences, Oct. 2015, pp. 27-30.

[91] E. Uhlemann, "Connected-vehicles applications are emerging [connected vehicles]," IEEE Veh. Technol. Mag., vol. 11, no. 1, pp. 25-96, Mar. 2016.

[92] J. C. Roberts, P. D. Ritsos, S. K. Badam, D. Brodbeck, J. Kennedy, and N. Elmqvist, "Visualization beyond the desktop-The next big thing," IEEE Comput. Graph. Appl., vol. 34, no. 6, pp. 26-34, Nov./Dec. 2014, doi:10.1109/MCG.2014.82.

[93] S. Webel, M. Olbrich, T. Franke, and J. Keil, "Immersive experience of current and ancient reconstructed cultural attractions," in Proc. Digital Heritage Int. Congr., Oct. 2013, vol. 1, pp. 395-398.

[94] J. Orlosky, M. Weber, Y. Gu, D. Sonntag, and S. A. Sosnovsky, "An interactive pedestrian environment simulator for cognitive monitoring and evaluation," in Proc. 20th Int. Conf. Intell. User Interfaces Companion, Mar. 2015, pp. 57-60.

[95] T. Hilfert and M. König, "Low-cost virtual reality environment for engineering and construction," Vis. Eng., vol. 4, no. 1, pp. 1-18, 2016, doi:10.1186/s40327-015-0031-5.

[96] J. Araullo and L. E. Potter, "Experiences using emerging technology," in Proc. 26th Aust. Comput.-Human Interaction Conf. Designing Futures, Dec. 2014, pp. 523-526.

[97] M. Čertický, M. Jakob, and R. Píbil, "Analyzing on-demand mobility services by agent-based simulation," J. Ubiquitous Syst. Pervasive Netw., vol. 6, no. 1, pp. 17-26, 2015.

[98] J. Wu, I. Yildirim, J. J. Lim, B. Freeman, and J. Tenenbaum, "Galileo: Perceiving physical object properties by integrating a physics engine with deep learning," in Proc. Adv. Neural Inf. Process. Syst. Conf., 2015, pp. $127-135$.

[99] V. A. Prabhu, A. Tiwari, W. Hutabarat, and C. Turner, "Capture, digitisation and segmentation of human-workpiece interactions in a manual assembly operation using Kinect ${ }^{\text {TM }}$," Int. J. Design Eng., vol. 6, no. 1, pp. 61-85, 2015.

[100] K. Lebeck, T. Kohno, and F. Roesner, "How to safely augment reality: Challenges and Directions," in Proc. 17th Int. Workshop Mobile Comput. Syst. Appl., Feb. 2016, pp. 45-50.

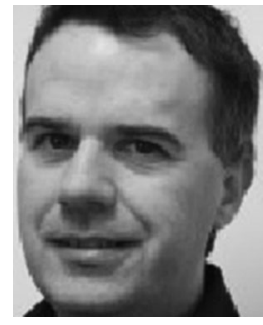

Christopher J. Turner (M'11) received the master's degree from the University of Sheffield, Sheffield, U.K., and the master's and Ph.D. degrees from Cranfield University, Bedford, U.K.

$\mathrm{He}$ is a Research Fellow and Project Manager with the Manufacturing and Materials Department, Cranfield University. His research interests include manufacturing simulation, manufacturing informatics, business process management, and business process optimization. With his involvement in the successful completion of several U.K. research councilfunded projects (with subjects ranging from business process optimization to the simulation of product-service systems), he is experienced in the management of commercially focused applied projects. He has published more than 60 papers in peer-reviewed international journals and conference proceedings.

Dr. Turner is a member of the IEEE Task Force on Process Mining.

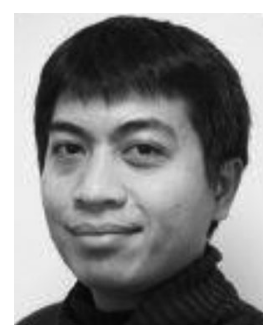

Windo Hutabarat has completed postgraduate research in the Engineering Design Centre, Department of Engineering, University of Cambridge, Cambridge, U.K. His first degree was from the Aerospace Department, Institut Teknologi Bandung, Indonesia.

$\mathrm{He}$ is a Research Fellow with the Manufacturing Informatics Centre, Cranfield University, Bedford, U.K., where he pioneered the idea of applying innovations from the gaming sector into manufacturing and services that resulted in multiple research and development projects funded by Innovate UK. His research interests include optimization, simulation, and computational intelligence.

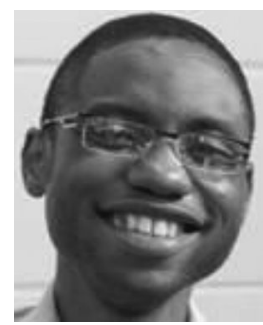

John Oyekan (M'09) received the Ph.D degree in robotics from the University of Essex, U.K.

$\mathrm{He}$ is a Research Fellow with the Manufacturing Informatics Centre, Cranfield University, Bedford, U.K. He has successfully worked on several EPSRC and Innovate UK projects in the areas of computational intelligence, robotics, and humanmachine interaction with various industrial partners such as Rolls-Royce, Airbus, Jaguar Land Rover, Alstom, and Holovis. His research interests include sensing and computational algorithms for various applications. He is currently investigating the use of low-cost gaming devices to improve productivity in manufacturing. Since 2008, he has authored/coauthored more than 29 publications.

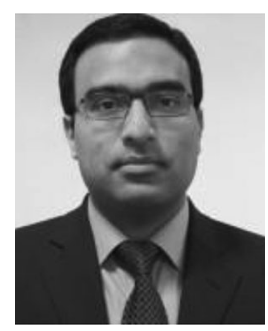

Ashutosh Tiwari (M'04) received the graduate degree in mechanical engineering from the Indian Institute of Technology, Kanpur, India, and the master's and Ph.D. degrees from Cranfield University, Bedford, U.K., in 1999 and 2001, respectively.

He is a Professor of manufacturing informatics and Head of the Manufacturing Informatics Centre, Cranfield University. His research interests include the development and application of informatics techniques for manufacturing technologies, processes, and systems. He has research expertise in the following areas: manufacturing informatics, manufacturing process optimization, engineering design optimization, application of gaming technologies to manufacturing, multiobjective optimization, and process modeling. He has authored/coauthored more than 222 research publications. 


\section{Discrete event simulation and virtual}

\section{reality use in industry: new opportunities and future trends}

\section{Turner, Christopher}

Institute of Electrical and Electronics Engineers

Christopher J. Turner, Windo Hutabarat, John Oyekan and Ashutosh Tiwari. Discrete event simulation and virtual reality use in industry: new opportunities and future trends. IEEE

Transactions on Human-Machine Systems. December 2016, Volume: 46, Issue: 6, pp882-894

http://dx.doi.org/10.1109/THMS.2016.2596099

Downloaded from Cranfield Library Services E-Repository 